\title{
Towards a mechanistic understanding of the responses of large terrestrial mammals to heat and aridity associated with climate change
}

\author{
Andrea Fuller ${ }^{1 *}$ (D), Duncan Mitchell ${ }^{1,2}$, Shane K. Maloney ${ }^{1,2}$ and Robyn S. Hetem ${ }^{1,3}$
}

\begin{abstract}
In the face of climate change, the life history traits of large terrestrial mammals will prevent them from adapting genetically at a sufficient pace to keep track with changing environments, and habitat fragmentation will preclude them from shifting their distribution range. Predicting how habitat-bound large mammals will respond to environmental change requires measurement of their sensitivity and exposure to changes in the environment, as well as the extent to which phenotypic plasticity can buffer them against the changes. Behavioural modifications, such as a shift to nocturnal foraging or selection of a cool microclimate, may buffer free-living mammals against thermal and water stress, but may carry a cost, for example by reducing foraging time or increasing predation risk. Large mammals also use physiological responses to buffer themselves against changing environments, but those buffers may be compromised by a changing physical environment. A decrease in the available food energy or water leads to a trade-off in which the precision of homeothermy is relaxed, resulting in large daily fluctuations in body temperature. Understanding how large mammals prioritise competing homeostatic systems in changing environments, and the consequences of that prioritisation for their fitness, requires long-term monitoring of identifiable individual animals in their natural habitat. Although body size predicts general ecological and energetic patterns of terrestrial mammals, high intraspecific and interspecific variability means that a species-directed approach is required to accurately model responses of large mammals to climate change.
\end{abstract}

Keywords: Thermoregulation, Homeostasis, Behaviour, Physiology, Heat, Water balance, Energy, Plasticity, Body mass

\section{Background}

Body size of mammals is positively correlated with extinction risk [1-3]. Many of the factors that predict extinction risk, such as home range size, population density, and reproductive rate are related to body size (Fig. 1). Using a decision tree to investigate extinction risk, Davidson et al. [1] showed that extinction risk increases rapidly for mammals when body mass exceeds $5.5 \mathrm{~kg}$. Although only about $15 \%$ of extant mammal species have a mass of more than $5.5 \mathrm{~kg}$, about $60 \%$ of all mammals thought to be at risk of extinction are heavier than that [1]. Conservation actions have slowed, or

\footnotetext{
* Correspondence: andrea.fuller@wits.ac.za

'Brain Function Research Group, School of Physiology, University of the

Witwatersrand, Johannesburg, South Africa

Full list of author information is available at the end of the article
}

even reversed, the decline of some large mammal species, but overall there still is an increasing number of species at risk of extinction [4]. Despite the creation of more areas that are protected, the large herbivore (above $5 \mathrm{~kg}$ ) population in Africa halved between 1970 and 2005 [5]. In an analysis of terrestrial carnivores, ungulates and elephants, Di Marco et al. [4] showed that for every species with improved conservation status, eight species have declined in status. The decline in conservation status has been worse for larger mammals than for smaller mammals, with species larger than $100 \mathrm{~kg}$ most at risk of extinction. Ungulate species have declined more than have carnivores [4], although Hilbers et al. [2] recently estimated a higher future probability of extinction for carnivorous than for non-carnivorous mammals of the same size. The threat to the large mammals that are apex consumers or ecosystem engineers is of 


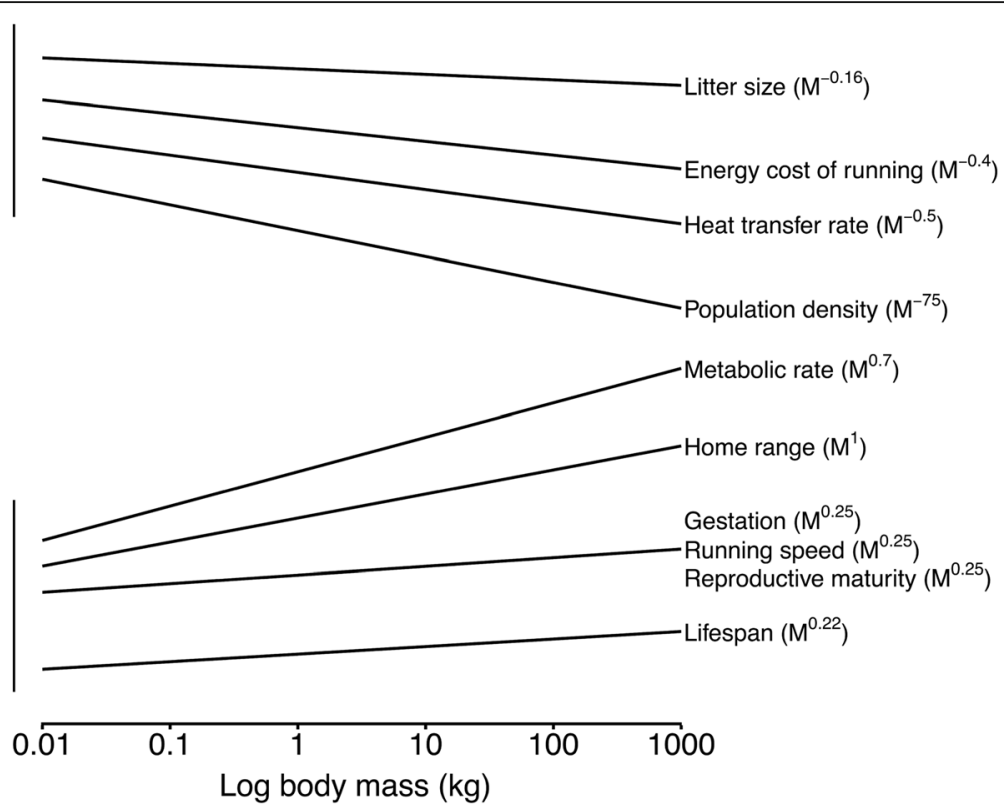

Fig. 1 Allometric generalizations for mammals, with slopes of lines showing fractional exponential power of body mass (M). Data from [39, 40, 44, 129]

particular concern, because they are critical for the normal functioning of ecosystems $[6,7]$.

Terrestrial mammals range in size from the pygmy shrew (Suncus etruscus) at about $2 \mathrm{~g}$ to the African elephant (Loxodonta africana) at $6500 \mathrm{~kg}$ [8]. Energetic constraints are believed to limit maximum body size of terrestrial mammals, with larger mammals requiring more energy, and therefore more land area, than do smaller mammals [9]. Larger mammals also have less body surface area for a unit of body mass, and therefore have slower heat loss per kilogram of body mass, in cool environments, than do smaller mammals [10]. There is a trend, therefore, for larger mammals to be over-represented in cooler habitats, at higher latitudes, as outlined by Bergmann's rule [11]. The largest mammals evolved when the Earth was cool and terrestrial land area was at its maximum extent [9]. A warming climate therefore may reduce the advantage of large size. Indeed, a decline in body mass is one of the universal responses (with range shifts and phenological changes) to the current climate change episode [12].

Climate change may affect species directly, for example, through the effects of heat on physiological tolerance and performance, or indirectly, for example, through changes in resource availability or pathogen distribution. Through its effects on life history, morphology, physiology and ecology, body size will influence how well mammals are able to buffer the effects of climate change. Although climate change may compromise larger mammals more than smaller mammals, as it has in the Earth's history [13], it will not influence all species of a given body mass to the same extent, and some species actually may benefit from climate change [14]. Understanding how different species will respond to climate change requires an understanding of their exposure and sensitivity to environmental change, as well as the plasticity available to them to buffer such changes. Some models predicting consequences of climate change have attempted to factor in the biological traits of species, but few have considered sensitivity and adaptive capacity of large mammals in responding to climate change. In this review we investigate the consequence of large body size (above $5 \mathrm{~kg}$ body mass) for free-living mammals in responding to the effects of climate change. Although shallow hibernation has been observed in bears [15], we focus here on mammals that do not use the hypometabolic states of torpor and hibernation to cope with reduced energy availability. The impact that environmental change and higher environmental temperatures will have on production mammals has been well documented, with decrements in growth and reproductive activity [16, 17]. While the mechanistic underpinning of these responses in production animals will be important in understanding the response of mammals in general, the artificial nature of production systems places those animals into a different context. We show that for many large free-living terrestrial mammals, range shifts and genetic adaptation are unlikely to provide a buffer to climate change. As a result, large mammals will be reliant mainly on the expression of phenotypic plasticity in situ to survive. Although some species may benefit through increased rainfall, increased plant productivity, and milder winters associated with climate change (for example, [18]), 
we focus here on how large mammals will respond to the stressors of increasing water shortage, food shortage, and heat. We explore how behavioural and physiological modifications may influence the vulnerability of large freeliving mammals to climate change.

\section{Range shifts}

Currently, habitat loss and degradation are the main threats to mammals, affecting the welfare of about $40 \%$ of mammal species [19]. In Europe, large mammals are predicted to lose 10 to $25 \%$ of their habitat by 2050 [20], while land-use change is expected to result in an $18 \%$ loss of land globally for carnivores by 2040 [21]. Climate change interacts with land-use change and can increase the impacts of land-use change on mammals [22].

The responses of mammals to habitat loss and fragmentation, while clearly evident retrospectively, are difficult to predict, especially without knowledge of the fundamental niche of a species [23]. Large terrestrial mammals, however, are likely to be more sensitive to the threat of habitat loss than are smaller mammals, because of their requirement for large home ranges, which are positively correlated to body mass (Fig. 1). For the same body mass, carnivores occupy larger ranges than do omnivores, and herbivores occupy the smallest ranges [24]. Home range area is likely a function of energetic needs, with larger mammals needing larger areas to provide the necessary energy resources $[24,25]$. The larger home range requirement of carnivores may result from their prey typically being less dense than are plants, although carnivore home range also may be influenced by the size of preferred prey, with smaller prey animals often occurring at higher densities [25]. Social organization also plays a role in determining home range area [26]. Social mammals, for example, may have smaller home ranges than do solitary species, but individuals may disperse over greater distances, possibly to avoid inbreeding [27]. Dispersal distance, the one-way movement to a new home range, also is positively correlated with body mass, particularly for herbivores and omnivores. Carnivores, however, typically disperse further than do herbivores and omnivores [27].

Locomotion is another important factor influencing home range, with faster-moving animals having larger home ranges [25]. Large mammals can move faster than can smaller mammals [28], and they move with a lower mass-specific energy cost [29] (Fig. 1). The mobility of large mammals therefore may make it easier for them than for smaller non-volant mammals to move and track suitable climates, as the climate changes. The displacement capacity of some carnivorous mammals and artiodactyls will likely be exceeded by climate velocity by the end of the century for most climate change scenarios [30]. Range shifts, however, will require suitable new habitats to be accessible from current habitats, for example, by being connected, and by the required travelling distance being within the capacity of the species shifting its range. Although new climatically-suitable habitat may be available near to the current range of some large mammals, others, like the scimitar-horned oryx (Oryx dammah), will be unable to move across the thousands of kilometers between their current and predicted future suitable habitats [31]. Some large mammals will be unable to shift their range because they have reached the edge of their suitable habitat; polar bears (Ursus maritimus) have declined at both their northern and southern boundaries as a result of loss of sea ice on which they depend for feeding [32]. Many large mammals also will be unable to shift their range, even to nearby habitats, as a result of human-made barriers to movement. The movement of large mammals, unlike smaller mammals and birds, is restricted by fences. For example, the migration of blue wildebeest (Connochaetes taurinus) in the Kalahari to major water sources that they once accessed routinely has been prevented by fence erection [33]. Those fences have been implicated in the mass die-off of $90 \%$ of the wildebeest population during the 1983 drought [34]. Indeed, for many large herbivores, under human-imposed constraints, home ranges are contracting and species currently occupy small fractions of their historical ranges [7].

The life history traits of large mammals also may influence their ability to colonise new habitats successfully. In a trait-based approach to modelling the potential spread of terrestrial mammals with climate change [35], litter size, the number of litters per year and population growth rate all were positively correlated with rate of spread, and all generally are lower in larger mammals than in smaller mammals (see below). Age at sexual maturity was inversely correlated with rate of spread, and large mammals mature later than do smaller mammals [35]. Thus, even if large mammals are able to move to new suitable habitats with relative ease, they may face difficulty in proliferating and establishing viable populations in the new habitat. If narrow or discontinuous corridors hinder the movement of a population of large mammals, the life history traits associated with their size may further reduce the likelihood of a successful range shift.

Where range shifts are not feasible for large mammals, either as a result of unattainable dispersal distances or loss of habitat connectivity, and the species cannot adapt in situ, assisted colonization may be a conservation solution to the threats imposed by climate change [36]. In particular, assisted colonization may be prioritized for species that perform critical ecological roles [37]. However, moving species to areas where they do not occur currently may introduce disease, alter species interactions that are required for normal ecosystem functioning, displace 
native species and deplete resources. The translocated species also may disperse outward to other areas [37]. Translocated mammals may experience severe physiological stress, and the impacts on the welfare of relocated animals are poorly understood [38]. An in-depth understanding of species' interactions, their biological requirements and physiological responses to translocation procedures is therefore required before the relocation of large mammals can become a routine procedure.

\section{Consequence of life history traits}

Life history traits influence not only the likelihood of range shift and population establishment, but also the adaptive capacity of large mammals to respond to climate change. Lifespan is correlated positively with body mass (Fig. 1) [39, 40], and the largest mammals can have lifespans that exceed those of the smallest mammals by eight-fold. Most bovids, cervids and carnivores live for 10-30 years in the wild, while hippopotamus, rhinoceros, primates and bears can live for 40 years, and elephants for 80 years [41]. Given the rate of climate change [42, 43], many individuals alive now will experience biologicallysignificant climate change within their expected lifetimes.

Reproductive traits also are strongly correlated with body mass in mammals. Larger mammals have longer gestation times, are older at sexual maturity, and have smaller litter sizes than do smaller mammals (Fig. 1) [39, 44]. With increasing body size, mammals breed less often, and do so less opportunistically [45]. In addition, larger mammals tend to have lower population densities and abundance (Fig. 1) [46]. Thus, although larger mammals often have a wider geographic range and can disperse over greater distances, the combined effect of their life history traits may place them at a greater risk of extinction than smaller mammals. Long generation time, small litter size, and delayed sexual maturity also hamper the capacity of large mammal populations to recover after a decline in their population [20].

While many of these life history traits place larger mammals at a disadvantage relative to smaller mammals, the most important implication of their life history traits, in the face of climate change, is their inability to adapt sufficiently fast through genetic change [47]. Natural selection acts on the fitness of a species, with genotypes with lower fitness expected to decline in frequency within the gene pool. The long time to sexual maturity, small litter size and long gestation period in large mammals results in a slow mutation rate and a slow production of new generations with favourable genotypes. Given the rapid rate of climate change [42, 43], it is improbable that those large mammals that are currently using their genotypic capacities to their fullest to cope with the climate of their current habitat can evolve features that support sufficient climate tolerance to remain in their current range. Even microevolution, the heritable shift in allele frequencies already present in a population, and not subject to the same time constraints as speciation, probably will not be sufficient to buffer large mammal populations against climate change [47]. Whether environmental factors can influence epigenetic processes in large mammals to lead to a heritable changes that buffer climate change effects also is not known [48]. As a result of not being able to move easily or to adapt genotypically, if they are to survive, many large mammals remaining in their changing habitats will be dependent on phenotypic plasticity. Below, we therefore consider the sensitivity and potential plasticity of large mammals to cope in situ as individuals with the major expected challenges that are expected to come, those of increased environmental temperatures, reduced water availability, and reduced energy availability.

\section{Responses to heat}

Mammals will be exposed to not only a progressively warming climate, but, superimposed on that, to more frequent and extreme heat waves and droughts [43, 49]. When the environment imposes a heat load on animals, which it will do increasingly as air temperatures rise, and especially for animals exposed to solar radiation, the only way for mammals to lose that heat and their metabolic heat is through evaporative cooling [11]. As a result, climate change that is accompanied by water shortage is likely to present a severe challenge to a mammal's homeostasis. Larger mammals have a smaller surface area to volume ratio than do smaller mammals, and therefore gain environmental heat at a lower rate, per kilogram of body mass, under environmental heat load than do smaller mammals. Large mammals also have more thermal inertia and lower mass-specific metabolic heat production. When exposed to high ambient temperatures and solar radiation, large mammals therefore experience a relatively lower perturbation of body core temperature [10].

Particularly for large mammals with high thermal inertia, a potential means to cope with daytime heat is to store the heat load rather than using water to evaporate it, and then dissipate that heat by non-evaporative avenues at night. Allowing body core temperature to rise during the day has an advantage in addition to conserving body water: rising body core temperature increases the gradient for dry heat loss to the environment or reduces the gradient for dry heat gain from the environment [50]. However, allowing body core temperature to increase progressively over a hot day increases the risk of heat-related illness and may reduce performance. The $\mathrm{Q}_{10}$ effect also means that metabolic rate increases as body core temperature increases, further increasing endogenous heat production [11]. Behavioural adjustments, 
such as shade-seeking, can reduce the heat load, but may come at a cost to other activities like energy and water acquisition. Understanding how large mammals will employ their potential responses to increased heat requires data not only from mechanistic studies conducted within the laboratory, but also data from freeliving mammals in their natural habitat, where they will be subject to a complex suite of stressors [51]. Below we describe the physiological and behavioural responses of large mammals to heat, with an emphasis on what has been revealed from large mammals living freely in the wild with access to drinking water. We consider later the responses of mammals that are exposed to both heat and water shortage.

\section{Physiological adjustments}

Largely as a result of iconic studies on captive camels (Camelus dromedarius) [52], eland (Tragelaphus oryx) and gemsbok (Oryx gazella) [53], it is widely held that large mammals respond to heat exposure by exhibiting hyperthermia, or "adaptive heterothermy", even when they are not water-deprived. Adaptive heterothermy (reviewed in [50]) refers to the state where an animal stores heat during the day, in so doing reducing evaporative water loss, and then dissipates that heat during the cool night by non-evaporative means, reaching a low that allows scope for substantial heat storage on the following day. As a result, body temperature fluctuates widely over $24 \mathrm{~h}$, between a higher than normal maximum during the day and lower than normal minimum at night. However, when body fluid homeostasis is not threatened, and there is sufficient food energy (see below), there would seem to be benefits for large mammals in the heat to maintain homeothermy. Measurements from large mammals with adequate food and water show that under these conditions they appear to prioritise homeothermy, maintaining body core temperature within relatively narrow limits. Captive baboons (Papio hamadryas ursinus), for example, with ad libitum access to drinking water, maintained the same body core temperature rhythm when exposed to a simulated desert environment as they did when exposed to $22{ }^{\circ} \mathrm{C}$ [54]. Similarly, in hot environments, body core temperature in free-living large mammals, across a broad range of species, varied by less than $2.5{ }^{\circ} \mathrm{C}$ over $24 \mathrm{~h}[50,51]$. Contrary to what might be predicted from the physical principles of body size, the increase in body core temperature across the day, which is reflected in the amplitude of the $24 \mathrm{~h}$ rhythm of body core temperature, is not correlated with the body mass of large free-living mammals with access to drinking water [55]. As shown in Fig. 2, the increase in body core temperature from its minimum to maximum value over $24 \mathrm{~h}$ in summer heat is not particularly different for mammals ranging in body mass from about $20 \mathrm{~kg}$ (springbok, Antidorcas

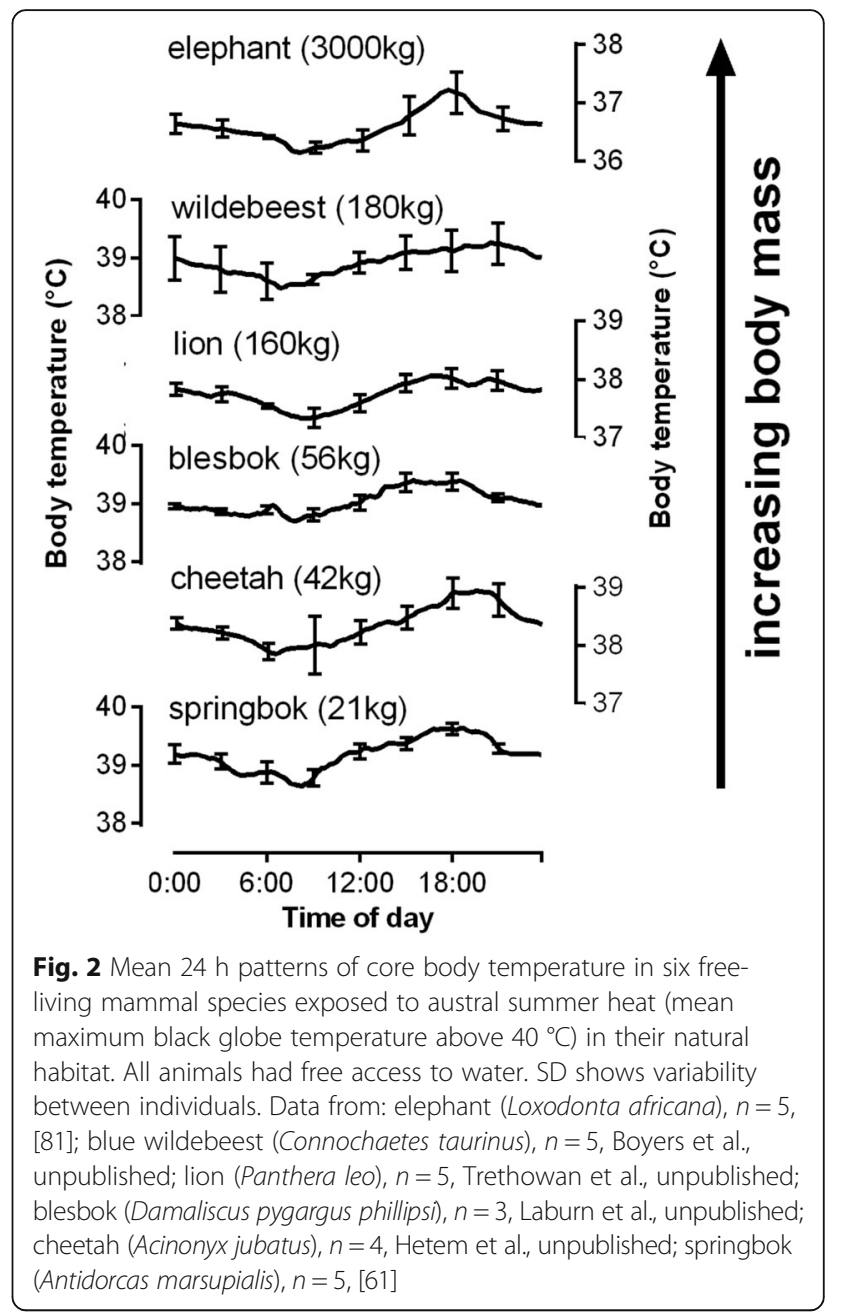

marsupialis) to about $3000 \mathrm{~kg}$ (African elephant). For a given rise in body core temperature, however, a larger mammal will store more heat than will a smaller mammal, and consequently may tolerate heat exposure for longer. Small mammals exposed to high solar radiation, like ground squirrels (Xerus inauris and Ammospermophilus leucurus), shuttle in and out of cooler microclimates (burrows) and thereby prevent excessive rises in body core temperature $[56,57]$.

In general, larger mammals regulate their body core temperature around a lower mean than do smaller mammals, potentially giving them greater scope for heat storage before a particular limiting body core temperature is reached. In an analysis of body core temperatures obtained from free-living large herbivorous mammals, we found that mean body core temperature decreased by $1.3{ }^{\circ} \mathrm{C}$ for each 10 -fold increase in body mass [55]. However, the relationship between mean body core temperature and body mass also is influenced by phylogeny. For example, marsupials and monotremes have a lower body core temperature than do eutherians of 
similar size [58]. Ant- and termite-eating eutherians, like aardvark and pangolins, also have lower body core temperatures than expected for their size [59]. Whether the set-point around which body core temperature is regulated by a large mammal changes with the geographic range of a species, or as a result of acclimatization to heat (as it does in humans, [60]), is not known. Moreover, it seems unlikely that the lowering of mean body core temperature by a couple of degrees will offer a significant buffer against a warming world. Indeed, in situations where environmental temperature exceeds body core temperature, which will occur with increasing frequency with climate change, a lower mean body core temperature will increase the gradient for dry heat gain.

A mammal's tolerance to heat is influenced not only by body size, but also by other morphological factors like pelage thickness and colour, as well as physiological mechanisms that change thermal conductance, such as the use of thermal windows and changes in peripheral blood flow. In environments cool enough for dry heat loss to occur, thermal windows, areas with low insulation that are highly vascularized (such as an elephant's ear), and peripheral vasodilatation can be used to facilitate heat loss [11]. In environments with high solar radiation, mammals with darker colouration absorb more short-wave radiation than do those with lighter colouration. In the same summer environment, black springbok gained more heat and had higher body core temperatures than did springbok of lighter colour morphs [61]. But the relationship between coat colour and heat gain from the environment is not simple, and is influenced by the depth to which radiation penetrates through the fur and the insulation between the point of absorption and the skin [62]. Springbok have a relatively thin pelage for their size [63]. A thicker pelage can act as a shield to radiation, preventing radiant energy from penetrating to the skin [11]. Removing the pelage by shearing during summer increased the water use of a camel by more than 50\% [64]. In red hartebeest (Alcelaphus buselaphus) exposed to high solar radiation, fur surface temperature reached $46{ }^{\circ} \mathrm{C}$ while skin temperature was only $40{ }^{\circ} \mathrm{C}$. The high surface temperature of the dense fur allowed most of the solar radiant heat to be dissipated by convection and radiation to the environment [65].

Despite the potential advantage of thick fur as a heat shield, large African mammals that can be exposed to high solar radiation throughout most of the year typically have thin or sparse fur [63]. The protective effect has to be balanced against the requirement to lose heat during high-intensity activity, when heat generation can be more than ten-fold that at rest. During high-intensity exercise, cheetahs (Acinonyx jubatus) [66] and impala (Aepyceros melampus) [67] rapidly dissipated heat, such that body core temperature rose by less than $1{ }^{\circ} \mathrm{C}$ during the exercise. Although cold-adapted large mammals shed fur and reduce pelage insulation (and subcutaneous fat) in summer, it is thought that they exhibit hyperthermia at relatively low ambient temperatures and are not able to dissipate heat rapidly following exercise. For example, experiments on captive moose (Alces alces) during the warm season revealed that animals reached the upper critical thermal limit of the thermoneutral zone (indicated by increasing metabolic rate) at an air temperature between 14 and $20{ }^{\circ} \mathrm{C}$ [68]. Care needs to be taken, however, in interpreting thermal limits obtained from studies on captive mammals, without proper access to behavioural thermoregulation [50]. With access to behavioural thermoregulation, moose selected shady and windy sites, and became sensitive to heat only at an air temperature of $24{ }^{\circ} \mathrm{C}$ [69]. Similarly, body core temperatures of trained polar bears walking on a treadmill exceeded $40{ }^{\circ} \mathrm{C}$, leading to the conclusion that polar bears store heat during exercise [70]. However, freeliving polar bears regulated body core temperature very well throughout summer, rarely exhibiting body temperatures above $39^{\circ} \mathrm{C}$ [71].

The upper critical limit of the thermoneutral zone has been advocated as an index to predict the sensitivity and vulnerability of mammals to heat associated with climate change (for example, [12, 72, 73]). However, it is unlikely that its thermoneutral zone is relevant in determining the vulnerability of a free-living mammal to climate change. The thermoneutral zone is determined in the laboratory as the range of dry-bulb temperatures at which metabolic heat production is lowest, and where a constant body core temperature can be achieved by dry heat loss only (that is, by altering skin blood flow) [74]. That zone is not applicable to an animal that is active, and its derivation ignores the complex suite of climatic factors, other than the dry-bulb temperature, that impact on heat exchange, including solar radiation, wind, and water vapour pressure. Additionally, just because evaporative water loss increases, as it does above the upper critical limit, does not mean that a thermal tolerance limit has been reached, or will be reached at a specific environmental temperature beyond that limit; evaporative cooling is a physiological, not a pathological response. The capacity of different species for evaporative water loss is not constant, and that capacity can change with acclimatization [75].

Indeed, where they have access to water, free-living large mammals appear to use evaporative water loss (see below) routinely to regulate body core temperature independently of environmental heat load [55]. They therefore routinely operate outside the boundaries of their laboratory-determined thermoneutral zones. Little is known about how the performance of free-living large mammals is influenced by hyperthermia, but avoiding hyperthermia presumably provides a safety margin against 
heat-related illness and supports physiological function [76]. The reproductive success of large mammals, which is crucial for their survival in changing environments (given their life history traits, discussed above), may be severely compromised by high body temperatures. In the male, an increase in testicular temperature reduces sperm output and results in decreased sperm mobility and abnormal morphology [16]. In females, heat stress disrupts the function of the oocyte and the follicle in which it is encased, as well as embryonic and foetal development [16].

Mechanisms of evaporative cooling differ between species of large mammals, and include panting, cutaneous water loss, and saliva spreading or wetting of the body. In general, larger body size is associated with increased use of cutaneous evaporation, with smaller mammals more likely to use panting [77]. The larger absolute surface area of large mammals better supports cutaneous evaporative cooling, which also provides a greater maximal rate of evaporative water loss than does panting [10]. Cutaneous evaporative cooling may occur by diffusion of water across the skin or by sweating. The largest of all terrestrial mammals, elephants, do not have sweat glands and lose water across a relatively permeable integument [78]. The cutaneous evaporative water loss of African and Asian (Elephas maximus) elephants is higher than that reported for any other arid-dwelling herbivore, and becomes obligatory at even relatively low air temperatures $\left(10-12{ }^{\circ} \mathrm{C}\right)$ [79]. Thus, rather than allowing their body core temperature to rise in the heat, as has been proposed [80], elephants appear to use significant evaporative cooling to keep body temperature relatively constant, even in very hot environments (Fig. 2) [81]. Indeed, epidermal permeability to water loss increased in elephants in summer, and in elephants exposed to higher environmental temperatures, indicating an acclimatization supporting heat loss rather than water conservation [79]. Domestic pigs also do not have thermally effective sweat glands [82]; whether large freeliving suids like warthog (Phacochoerus africanus) can employ physiologically significant diffusive evaporative cooling is unknown.

Among mammals, sweating capacity is highest in equids and some primates, including man, and supports dissipation of the high metabolic heat load of exercise, especially when exercise is undertaken in the heat $[10,83]$. Freeliving zebras (Equus burchelli) maintained body core temperature within a narrow daily range in hot environments despite remaining active over the day [84]. Their apparent reliance on sweating means that they do not extend into arid zones and appear to be among the most water-dependent of large mammals [8]. Sweating also is an important route of heat loss for bovids and camelids [10], although some species also use panting, with the reliance on panting inversely proportional to body size [77].
Eland, for example, use sweating as the main means of evaporative heat loss, while the smaller red hartebeest relies more on panting [65]. Two of the smallest antelopes, the dik-dik (Rhynchotragus kirkii) and the suni (Nesotragus moschatus), use only panting [85]. Panting also is common in carnivores [10]. Thick fur impedes the evaporation of water, so panting is more effective for many coldadapted large mammals. In desert environments, however, the dry environment facilitates evaporative water loss even from furred mammals like antelope and camels [10]. Some mammals can switch between different routes of evaporative water loss; kangaroos, for example, sweat during exercise but pant at rest in the heat [86].

Kangaroos, and many other marsupials, also salivate profusely and spread saliva across well-vascularised regions of their bodies when exposed to heat. Red kangaroos (Macropus rufus) lick their highly-vascularised forearms and legs [87]. Wallowing in mud also offers a means to cool the skin, as the water evaporates, and is critical for pigs, which do not sweat and dissipate only a small percentage of their heat production by respiratory evaporation [82]. Bathing or wallowing in mud, as seen in elephants [79], also may be employed to further increase cutaneous evaporative heat loss. The advantage of this wetting behaviour is that body water is not used, but it does require a mammal to have ready access to free-standing water. Evaporative cooling by any mode also requires vapour pressure on the mammal's skin to be higher than that of the environment. In mammals occupying hot and humid environments, or microclimates with high vapour pressure, evaporative cooling will be reduced.

In summary, when evaporative cooling is available to a large mammal, it appears to be sufficient to dissipate the combined heat load from metabolism and the environment, even in very hot environments. Nevertheless, to enable evaporative cooling in the face of climate change, overall, many large mammals are likely to become more dependent on available water resources in their habitats. Because evaporation is the only route available for heat loss when environmental temperature exceeds body temperature, mammals that are not able to source water readily will have a greater reliance on behavioural, rather than physiological, modifications to cope with hotter environments.

\section{Behavioural adjustments}

The first response of many animals to hotter environments will be to escape the heat through seeking cooler (and often more thermally-stable) microclimates. Successful buffering of climate change through exploitation of cooler microclimates will require that the behaviour does not compromise life cycle, energy, or water requirements, and that cooler microclimates are accessible to 


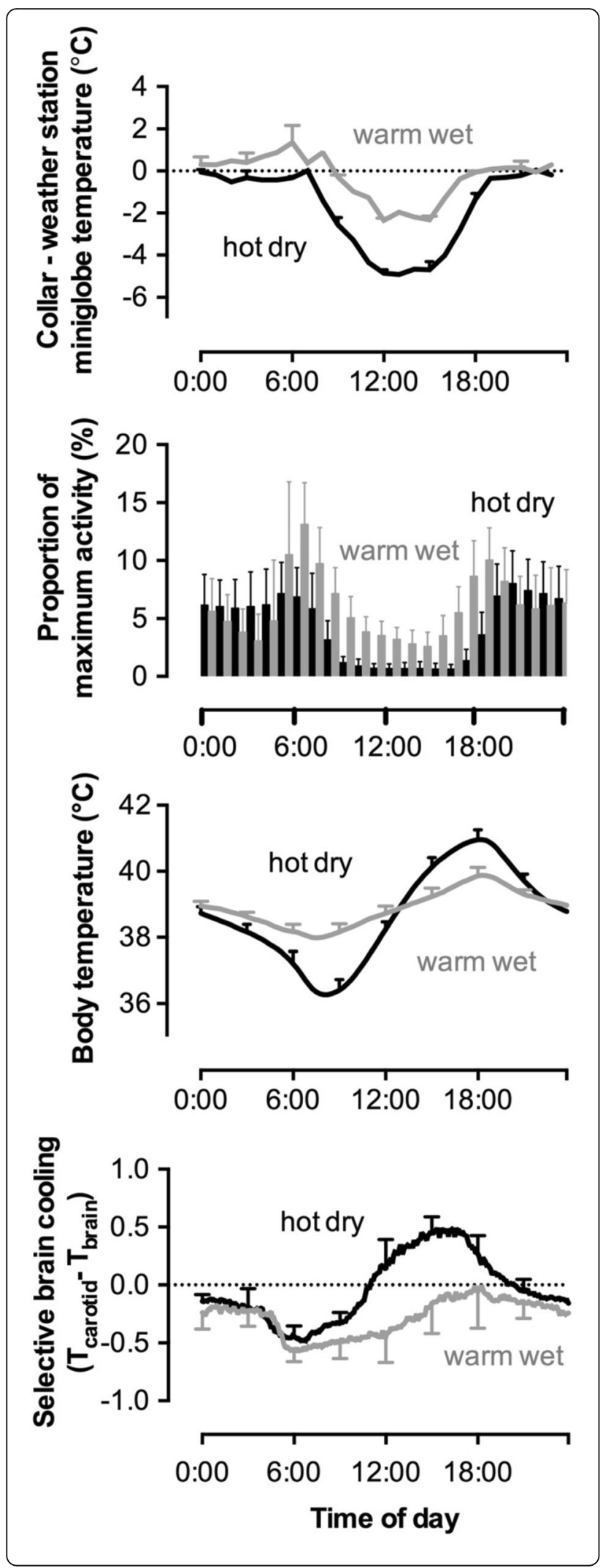

Fig. $324 \mathrm{~h}$ patterns of microclimate selection (expressed as the difference between collar miniglobe temperature and weather station miniglobe temperature, $n=2$, points below the zero line represent selection of cool microclimates), activity (expressed as a proportion of maximum activity recorded, $n=5)$, core body temperature $(n=5)$, and selective brain cooling $(n=1)$ in Arabian oryx (Oryx leuconyx) in a hot, dry period and a warm, wet period. Data from $[91,115,120]$

the animal. Unfortunately for large mammals, the variety of microclimates available to an animal decreases with increasing body size. Small mammals have greater access to burrows, holes, crevices, caves and habitats below vegetation than do large mammals. In general, increasing body mass of mammals coincides with a decreased ability to "sleep-or-hide", a term used to describe substantial lowering of metabolic rate (e.g., during torpor and hibernation) and hiding behaviour (e.g., in burrows) [88]. Because of the plasticity in this behaviour, it is predicted that small mammals that employ "sleep-or-hide" are likely to cope better with climate variation [88]. However, while some large mammals, such as aardvark, foxes, and hyenas, do not use torpor or hibernation, they can access refuges like burrows and dens.

The hiding behaviour of small mammals is used primarily to escape from solar radiation, the dominant factor influencing environmental heat gain of many mammals [10]. Shade-seeking, another method to reduce radiative heat gain, is available to even the largest of mammals $[47,89]$. In the very hot desert environment of Saudi Arabia, Arabian oryx (Oryx leucoryx) sought shade as early as 06:30 in the morning (within an hour after sunrise), and were observed to be in shade for more than nine hours of the day, moving away from trees only when air temperature was lower than body core temperature, and heat therefore could be dissipated by non-evaporative means [90]. Through the use of biologgers to detect microclimate selection without human observers, we also have shown that Arabian oryx selected cooler microclimates with increasing environmental temperatures (Fig. 3) [91], and at times accessed microclimates with a black globe temperature (which integrates the effects of air temperature, radiation, and wind speed; [92]) as much as $12{ }^{\circ} \mathrm{C}$ below that of the open environment. In dry periods in which the oryx had no access to drinking water, they selected cooler microclimates than they did at the same environmental heat load in wetter periods, when they had access to drinking water [91]. Shade-seeking, therefore, may become more common in the face of climate change, if habitats continue to offer sufficient thermal refuges. Free-living Angora goats (Capra aegagrus) occupying a habitat transformed by previous heavy browsing (and similar to that likely with hotter and drier climates) were less 
able to access microclimate refuges than were Angora goats in an adjacent pristine habitat. As a result, goats in the transformed habitat were more water-dependent and experienced larger increases in body core temperature over the day than did the goats in the pristine habitat [93]. Both the number of microclimate refuges and the quality of the shade are likely to decrease in regions that will experience reduced precipitation with climate change.

Given that larger mammals experience a lower massspecific environmental heat load and have a lower mass-specific metabolic rate than do smaller mammals, one might predict that the threshold environmental temperature for shade-seeking will be dependent on body mass, with larger animals seeking shade at higher temperatures. In African elephants in the Okavango Delta (with freely available water), the probability and duration of shade use increased when black globe temperature exceeded $35{ }^{\circ} \mathrm{C}$ [94]. Kudu antelope (Tragelaphus strepsiceros), despite being much smaller than an elephant, sought shade at a similar globe temperature when exposed to summer heat, with access to drinking water [95]. Similarly, despite being about four-fold smaller in size than Arabian oryx, Arabian sand gazelles (Gazella subgutturosa marica) in the same desert environment as the oryx sought shade at the same globe temperature $\left(28^{\circ} \mathrm{C}\right)$ as did the oryx [96]. Red and western grey (Macropus fuliginosus) kangaroos of similar body mass retreated to shade at different radiant heat loads, with red kangaroos apparently more tolerant of radiant heat [97]. The data available to date therefore imply that the relationship between body mass and shade-seeking will not be a simple one. Differences in morphology, including colour and thickness of fur, and prior exposure to arid environments, may influence the threshold for shade use. Mammals also typically have to trade off shade seeking with other activities, such as feeding and drinking.

For large mammals that do not retreat to shade during the heat of the day, either because they don't have access to shade or because other activities are mutually exclusive with shade-seeking, changes in body orientation and posture can reduce solar heat load by reducing the body surface area exposed to radiant heat. Black wildebeest (Connochaetes gnou), for example, oriented the long axis of their body towards incoming solar radiation, allowing them to reduce radiant heat gain by about 30\% [98]. Similarly, the conventional-coloured springbok, which has a white face and rump with darker flanks, oriented its body parallel to the sun, thereby reducing radiant heat gain, at midday, but perpendicular to the sun in the morning, and in doing so offset the metabolic costs of increasing body temperature [99]. Large mammals also may differentially expose body regions with features (such as their surface area, insulation, and colour) that allow those areas to act as "thermal windows". For large ungulates with thick body fur, limbs, which have a higher surface-to-volume ratio, higher convective and evaporative heat transfer coefficients, and less insulation than does the trunk, may provide a significant avenue for heat loss [10, 11].

In the face of high diurnal heat loads, another option available to large mammals is to transfer activity to the night $[89,91]$. The timing of an animal's behaviour is determined by the interaction of outputs from its internal circadian clock, with that of masking, the direct stimulation or inhibition of behaviours by environmental factors [100]. Temporal niche switching has been observed in many animal species in response to changes in environmental temperature, season and food abundance. However, little is know about whether phylogeny might constrain the ability of some mammals to switch their temporal niche. What is known is that few mammalian species are equally adapted to nocturnal and diurnal conditions [100]. Innate properties related to the animal's physiology and anatomy, such at the ability to see at night, therefore may limit temporal niche switching. For example, some mammals may be able to engage in nocturnal activity only on moonlit nights.

For mammals that can switch to nocturnal activity, nighttime feeding offers the potential benefit of foraging on wet vegetation [89] or plants with higher water content [101]. However, a switch away from diurnal activity also may compromise energy acquisition if it results in a reduction in the animal's total $24 \mathrm{~h}$ activity, and therefore foraging time. Determining whether total $24 \mathrm{~h}$ activity is altered requires continuous and remote measurement of activity patterns in free-living mammals. Using collars equipped with activity sensors, Bourgoin et al. [102] found that mouflon (Ovis gmelini musimon $\mathrm{x}$ Ovis $s p$.) in a Mediterranean region shifted to more nocturnal activity during hot periods, but decreased total $24 \mathrm{~h}$ activity in doing so. The moufflon were unlikely to have been able to compensate for the decreased feeding time by increased feeding efficiency. In contrast, in a period of extreme heat and aridity, Arabian oryx (Fig. 3) and Arabian sand gazelles shifted from a biphasic or crepuscular pattern of activity to a nocturnal pattern, without reducing total $24 \mathrm{~h}$ activity [91, 96]. Surprisingly, patterns of activity across $24 \mathrm{~h}$ and across seasons were almost identical in the large, grazing Arabian oryx and the smaller mixed-feeding Arabian sand gazelle. These data therefore do not support widely-held views that the feeding time of herbivores, reflected by time active, is tightly associated with body mass or feeding style [96].

The transfer of activity between periods of the day, or cathemerality (as it has been termed for primates, [103]), may offer an effective means for large mammals to reduce environmental heat gain. An analysis of mammalian responses to climate change revealed that species 
that exhibit flexibility in activity times were less likely to respond negatively to climate change [14]. The opportunity for large mammals to shift activity to night, however, may be constrained by factors such as the energetic costs of being active over the cooler night, predation, or night vision ability. A benefit of their size, however, is that heat is lost relatively slowly during the cool night. Indeed, body temperature of large free-living ungulates exposed to cool nights with clear skies was higher, on average, at night than it was during the day [50]. However, if energy intake is reduced as a consequence of climate change, a trade-off may be required between the maintenance of homeothermy and energy balance (see below). A trade-off also may be required with predation costs. Unlike Arabian oryx and sand gazelles, which had no predators in their natural environment, a shift to nocturnal activity for many other large mammals may come with increased predator encounters [90]. Behavioural adjustments to heat therefore are difficult to predict without an understanding of the trophic relationships between species, as well as a detailed understanding of how trade-offs associated with alterations in behaviour influence a mammals's performance in its natural habitat.

\section{Responses to water shortage}

In addition to the warming with climate change, areas of Central America, northeastern South America, the Mediterranean, west Africa, southern Africa, and southwestern Australia are expected to experience an increase in the frequency of extremely dry seasons, while many northern hemisphere areas will experience reduced snow [43]. Hotter and drier environments may affect a mammal's water balance directly, for example through reduced drinking water and an increased demand for evaporative cooling, and indirectly, for example through a decrease in water obtained from food or reduced shade availability. Physiological and behavioural mechanisms for dealing with reduced water, like those used by desert mammals $[89,104]$, therefore are likely to become more ubiquitous in large mammals across a broader geographical range.

\section{Physiological adjustments}

If mammals do not have access to readily-available drinking water, the dehydration resulting from evaporative cooling compromises physiological function and can result in mortality. The dissipation of heat by evaporation results in proportionally greater dehydration in smaller mammals than it does in larger mammals, meaning that fossorial or nocturnal activity is obligatory for many small mammals in hot and dry environments [105]. Conversely, large mammals dehydrate more slowly, and their lower mass-specific surface area results in a lower rate of heat gain from hot environments and therefore relatively less water is required to dissipate the environmental heat load [106]. Water-deprived large mammals also may significantly reduce water lost in faeces and urine [89]. For example, dehydrated Arabian oryx reduced urine volume by $40 \%$ and faecal water content by $5 \%$, resulting in a saving of $550 \mathrm{~g}$ of water per day [107].

Despite these advantages, a common response of large mammals to water deprivation is a reduced rate of sweating and panting $[10,89]$. For example, in response to a 5-month period of water and food restriction, Arabian oryx reduced total evaporative water loss by 26\% [107]. Evaporative water loss can be reduced either by reducing the rate of evaporation at a given body temperature, or by increasing the threshold body temperature at which sweating and panting is initiated [108]. In eland that were exposed to heat when dehydrated, the initiation of sweating and panting was delayed until skin temperature reached a higher threshold than when they were hydrated. At the same time the sensitivity of the panting response was enhanced in dehydration compared to hydration, such that at the same body core temperature, small increments in skin temperature above the threshold resulted in a greater increase in panting [108]. If dehydrated mammals are to maintain homeothermy when evaporative heat loss is reduced, dry heat loss has to increase or dry heat gain be prevented. An advantage of a lower sweating rate is a higher skin temperature, which will increase the gradient for dry heat loss from the skin to the environment or reduce the gradient for dry heat gain [109].

One physiological mechanism for reducing evaporative water loss, that is available to some large mammals, is the implementation of selective brain cooling, a mechanism with the advantage of being quickly reversible [51, 110]. The anatomical structure that supports selective brain cooling in large mammals, the carotid rete, is welldeveloped in artiodactyls and felids. The thin walls and large surface area of rete vessels facilitate rapid exchange of heat from the arterial blood destined for the brain to cool venous blood draining from the nasal mucosa and other areas of the head, such that the temperature of the brain (measured at the hypothalamus) can be lowered below that of arterial blood [50, 110]. In mammals that do not possess a carotid rete, including perissodactyls, primates and most small mammals, hypothalamic temperature consistently exceeds carotid arterial blood temperature, usually by about $0.5{ }^{\circ} \mathrm{C}$ [111]. By lowering the hypothalamic temperature, and therefore the temperature of thermo-sensors there that provide a major drive on evaporative cooling mechanisms, selective brain cooling reduces evaporative water loss. Selective brain cooling of $0.5^{\circ} \mathrm{C}$, as typically achieved in free-living mammals [50], reduced daily respiratory evaporative water loss 
of goats by $0.7 \mathrm{l}$, saving $35 \%$ of their daily water intake [112]. In dehydrated artiodactyls, selective brain cooling is enhanced $[109,111]$, leading to even greater water savings. By using selective brain cooling for more than $50 \%$ of the day, dehydrated heat-exposed sheep reduced their water loss by about half [113].

Selective brain cooling has been observed in domestic cats [114], but whether free-living felids implement selective brain cooling as a water conservation mechanism, as artiodactyls do, is not known. In free-living artiodactyls, selective brain cooling is implemented most commonly in the afternoon, when body core temperature is rising slowly and the animals typically are engaging in low levels of activity [50]. As a water-saving mechanism it may provide an advantage to large mammals facing climate change. In Arabian oryx, the use of selective brain cooling was enhanced in a hot, dry period compared to in a warm, wetter period (Fig. 3) [115]. It also was greater than that in the closely-related gemsbok, which inhabited a grassland habitat with similar environmental temperatures but three times as much rainfall [116], and it was exhibited at a threshold body core temperature lower than that measured in African antelope in more mesic environments [115]. Whether the enhanced selective brain cooling in Arabian oryx compared to that in African antelope has an anatomical or functional basis is not known. There is considerable variability in carotid rete anatomy between artiodactyls; in one family, the mouse deer (Tragulidae), a carotid rete is absent [117]. In three African antelope species reported to have varying water dependency, carotid rete morphology did not differ and the capacity to implement selective brain cooling, at least in an environment that provided access to drinking water, was similar [118]. It has been argued that the evolutionary success of artiodactyls, relative to that of perissodactyls, might be attributed partly to the presence of a carotid rete and the resultant water saving capability [119]. Mammals without a carotid rete, like zebras and primates, may not be able to venture as far from water as artiodactyls without risk of compromising their body water balance. Early hominins may have been able to venture far from water in spite of not having a carotid rete by carrying water or water-rich plant matter [54].

Reducing evaporative water loss in hot, dry environments implies that large mammals prioritize osmoregulation over the maintenance of a constant body core temperature [55]. A decrease in metabolic heat production in dehydrated large mammals $[109,111]$ may reduce the extent of hyperthermia when evaporative cooling is reduced. Nevertheless, as shown originally for camels [52], and subsequently in other large captive mammals [50], the maximum daily body core temperature progressively increases when mammals are deprived of water. A similar pattern is evident in free-living large mammals experiencing water shortage. Free-living Arabian oryx and Arabian sand gazelles without access to water exhibited larger daily changes in body core temperature, allowing $24 \mathrm{~h}$ maximum body temperature to increase above that recorded when the animals were hydrated $[96,120]$. As shown in Fig. 3, Arabian oryx reached a higher body core temperature in a hot, dry period compared to when it was warm and wet. A depression of the $24 \mathrm{~h}$ minimum body temperature also was evident in the hot, dry period, but that reduction is likely to represent a failure to maintain $24 \mathrm{~h}$ minimum body temperature in response to energy deprivation (see below), rather than an adaptive response to increase heat storage capacity [55]. In Arabian oryx in a desert environment, the period of lowest water and lowest energy availability coincided in summer.

Dehydration-induced hyperthermia may impair performance and increase the risk of heat illness. With the exception of humans, little is known about how high body core temperatures influence performance in large mammals, and what body core temperature represents a lethal limit. In large free-living mammals, the highest body core temperatures that have been recorded, as far as we are aware, are about $42.5{ }^{\circ} \mathrm{C}$ in exercising black wildebeest [121] and water-deprived Arabian oryx [120]. Those body temperatures are likely very close to those that will result in heat-related illness. In the laboratory, dogs and cats succumbed to heat at rectal temperatures between 41.0 and $43.5{ }^{\circ} \mathrm{C}$ [122], and baboons experienced signs of heatstroke at $42.5{ }^{\circ} \mathrm{C}$ [123]. In a desert environment, baboons became socially dysfunctional after a few days without drinking water [124].

When drinking water was returned to heat-exposed baboons in a climatic chamber after three days of water deprivation, body core temperature fell immediately [54]. The fall was not a direct calorimetric effect of cool water ingestion, because the drinking water was at the same temperature as the baboon's body core. A similar rapid fall in body core temperature was observed in dehydrated sheep and goats on the return of warm drinking water, and probably represents rapid activation of evaporative heat loss mechanisms and cutaneous vasodilation [111]. In neither the sheep and goats nor the baboons was the fall of body core temperature dependent on the restoration of body fluid osmolarity; it occurred before the water was absorbed. Ruminants, like the sheep, goats, and Arabian oryx, may have an advantage over other large mammals during water shortage because the rumen allows the exact replenishment of lost water even in one drink, and it provides a reservoir to buffer the first few days of water deprivation [89, 104]. Camels and Bedouin goats can survive water losses of 30 to $40 \%$ of body mass, while a body mass loss of $15 \%$ can 
result in mortality in other large mammals [89]. Modelling the responses of large mammals to water deficit in hot enviornments therefore requires a detailed knowledge of the species' physiological plasticity.

\section{Behavioural adjustments}

Large mammals in hot, dry environments also may implement behavioural modifications to reduce evaporative water loss or to increase water intake. As described above, behavioural modifications in response to heat include the selection of cooler microclimates, with shade being particularly important for large mammals, as well as postural changes and a shift towards nocturnal activity. During a very hot and dry summer, Arabian oryx sought shade throughout the day and shifted all activity to the night (Fig. 3, [91]). At this time of year, Arabian oryx obtain about a quarter of their water from metabolic water and about three quarters from pre-formed water in grasses, which have a water content of about $46 \%$ [125]. The selection of succulents or plants with higher water content, if available, may increase water influx in large desert mammals [101, 126]. Carnivores also may be able to supplement drinking with fluids from prey. Leopards in the Kalahari desert, for example, can go without drinking for up to 15 days [127]. Rather than tracking climate change independently, therefore, large carnivores may instead follow their prey [31]. Obtaining water through the diet offers the advantage of meeting both energy and water needs through a single activity. In hotter and drier climates, however, many large mammals will be faced with a concomitant decline in both drinking water and food. Also, when their water balance is compromised, mammals will have to weigh up the costs of obtaining more water from food with the costs of searching for that food, with higher activity likely to require higher evaporative water loss to offset heat from the environment and metabolic heat production.

\section{Responses to reduced energy}

The rate at which mammals obtain and expend energy is an important determinant of their population distribution, and fitness correlates such as body condition, conception rate, perinatal condition, and survival of young [128]. As mammals increase in size they require more energy to meet maintenance, reproduction, and locomotion demands [129]. Climate change can affect the energy balance of large mammals by altering the quantity and quality of food, as well as its spatial distribution $[128,130,131]$. Changes in species ranges or microclimates selected within a habitat may alter predator-prey overlap and competition between species for food sources $[128,131]$. Changes in the temporal distribution of food also are likely with climate change. Most large mammals confront seasonal variations in their environments and it is critical for them to match the timing of reproduction with expected peaks in resource availability [132]. Where their reproductive cycle is determined by photoperiod [132] but the timing of food availability is altered by a changing climate, a trophic mismatch may occur (for example [133]). Behaviours necessary to cope with hotter and drier environments, such as shade-seeking, also may force large mammals to reduce foraging time. Indeed, Speakman and Król [134] have proposed that in many situations trade-offs in energy acquisition for endotherms are governed mainly by the capacity of the animal to dissipate heat and avoid hyperthermia. Given that large mammals have proportionally more body fat, and a lower mass-specific metabolic rate than do smaller mammals, they are able to endure fasting for longer [129]. Nevertheless, in the face of sustained energy shortage, physiological and behavioural adjustments are required if large mammals are to defend body condition and ensure reproductive success [135].

\section{Physiological adjustments}

In large mammals, a major contributor to daily energy expenditure is the resting metabolic rate [134], and a common response to insufficient energy availability appears to be a decrease in that metabolic rate. Pronounced seasonal fluctuations in metabolic rate, as indexed by heart rate, have been observed in moose, Alpine ibex (Capra ibex ibex), red deer (Cervus elaphus) and horses (Equus ferus caballus and E. ferus przewalskii) in winter $[68,136-139]$, when the animals have to cope with low quality and difficult to access (e.g., if covered with snow) plant material. In desert environments, food availability closely follows precipitation, so large desert mammals typically experience insufficient food not during winter, but during summer, at a time when they are not exposed to cold stress. Consequently, Arabian oryx [125], Arabian sand gazelles [138], and springbok [101] reduced metabolic rate during the dry summer months. In Arabian oryx, for example, the field metabolic rate in summer was almost half that of what it was after rains when grasses were green [125]. Whether large mammals reduce their metabolic rate in advance of seasonal food energy restriction to facilitate weight gain, as has been observed in Arctic ground squirrels [140], is unknown.

Maintaining homeothermy is energetically demanding, and maintaining a high body core temperature adds costs in cold environments. It is therefore not surprising that in addition to a lowered metabolic rate, lower rumen temperatures in Alpine ibex [137] and lower subcutaneous temperatures in red deer and horses [136, 138, 139] were evident in winter. Even in a benign African environment, free-living springbok exhibited lower body core temperature in a dry winter [141]. Low ambient 
temperature itself, however, does not appear to have been the main factor responsible for the reduced body temperatures. In winters as cold as those faced by hypothermic red deer, horses and Alpine ibex, pronghorn antelope (Antilocapra americana) receiving supplementary food maintained body core temperature within a narrow $24 \mathrm{~h}$ range, with the $24 \mathrm{~h}$ minimum body core temperature higher than that in summer [142]. A reduction in body core temperature also was evident in Arabian oryx (Fig. 3, [120]) and Arabian sand gazelles in summer [96, 143], when environmental heat load was high but food was scarce. Similarly, free-living western grey kangaroos had lower $24 \mathrm{~h}$ minimum body core temperatures in summer, a dry season in their Australian habitat with reduced plant growth, than in winter [144]. Polar bears facing reduced food availability in summer also exhibited a gradual decline in body core temperature of about $1{ }^{\circ} \mathrm{C}$ [71]. Energy deficit, rather than cold, therefore appears to drive the fall in body core temperature.

That relationship is supported by experiments manipulating the food intake of large mammals. Reducing energy intake to about $70 \%$ of maintenance energy requirements decreased the body core temperature of sheep (Ovis aries) by about $0.5{ }^{\circ} \mathrm{C}$ [145] and rectal temperature of horses (E. ferus caballus) by $1{ }^{\circ} \mathrm{C}$ [139]. Rectal temperature fell similarly in starved goats and sheep [146]. While the substantial falls in body core temperature that occur in small mammals during torpor may prevent mortality, the lowering of body core temperature in large mammals with continued energy deficit may not be sufficient for survival. Whiteman et al. [71] determined that the energy saving resulting from the $1{ }^{\circ} \mathrm{C}$ fall in body core temperature of polar bears would be insufficient to prevent a decline in body condition with continued ice loss. In large antelope with insufficient energy, body core temperature progressively fell over several days, with the animals dying in the morning, when they faced increasing energy demands for rewarming [55]. Heterothermy associated with a declining $24 \mathrm{~h}$ minimum body temperature in large mammals therefore appears to reflect an inability to maintain body core temperature, rather than a controlled thermoregulatory event like that seen in torpor [55].

The reduced metabolic rate in large mammals experiencing restricted food supply appears to be attributable partly to a consequential decrease in the mass, and therefore metabolic activity, of visceral organs, including the alimentary tract and rumen papillae [147]. Red deer, which fed less during winter, compensated for that reduced feeding, and the change in visceral organ size, by improving extraction of nutrients from food [147]. In Arabian sand gazelles, a decrease in liver, heart, and muscle masses contributed significantly to a decrease in standard fasting metabolic rate when they were food- and water-restricted. The mass of the intestine and rumen did not change, however, perhaps reflecting an adaptation of desert mammals enabling them to adjust rapidly in the event that food becomes available after rain [148]. Whether the responses involved in acclimatization to seasonal changes in food availability will be sufficient to buffer mammals against greater food deficits likely with climate change, or unpredictable changes in food resources, is not known.

\section{Behavioural adjustments}

In environments where large mammals face an energy deficit, behavioural modifications may be used to supplement physiological modifications in reducing energy expenditure. Red deer and horses, for example, decreased energy expenditure in winter by lowering metabolic rate and by decreasing locomotor activity $[136,139]$. In contrast, there was no change in the total $24 \mathrm{~h}$ activity of Arabian oryx and Arabian gazelles over a year [96, 120], and some animals may counteract imminent starvation through increased foraging efforts or activity for migration [135]. Microclimate selection and behaviours that alter thermal conductance (for example, postural changes or huddling [11]) also can be used to reduce energetic costs of maintaining body temperature in winter [149], or during the early morning when environmental temperatures are lowest. In the cold, orienting perpendicular to solar radiation may be used to offset the metabolic costs required to maintain body temperature [98], and may be particularly beneficial in large mammals with sparse fur coats (and hence, little insulation) or of dark colour. Black springbok, a naturally-occurring colour morph, spent less time foraging during winter than did the two lighter colour morphs (common and white springbok), likely reflecting a lower metabolic requirement for maintaining homeothermy. The black springbok were able to obtain nearly twice the energy flux from solar radiation than could the white springbok [61]. Anecdotal reports indicate that black springbok survive cold winters better than do the other colour morphs.

Accessing solar radiation through basking typically is considered an adaptive behaviour of small mammals, and of ectotherms. For small mammals, basking significantly reduces the energy cost of rewarming and the energy cost of maintaining a constant and high body temperature in the cold [11]. However, evidence is emerging that basking also may provide an important strategy for large mammals, particularly over winter or in response to food shortage. Alpine ibex use basking as a means to increase body temperature while sparing crucial fat reserves during winter [137]. We also have observed food-deprived aardvarks (Orycteropus afer) basking in the early morning, at a time when they are usually in burrows (Weyer et al., University of the 
Witwatersrand, unpublished observations). Whether basking behaviour is a profitable adaptive mechanism available to other large mammals facing energy deficits is not known. If it is, it may be an indicator of inadequate energy availability, and therefore a useful measure of species' responses to climate change.

\section{Developing a mechanistic understanding of responses to climate change}

Studies on the physiological and behavioural responses of free-living large mammals in their current habitats have revealed insights into how individuals may respond to heat and aridity associated with climate change. As a current analogue of the kind of environment likely in a climate-changed future, Arabian oryx in the hot, dry summer in the deserts of the Middle East face the combined stressors of water shortage, food shortage, and heat. Despite exhibiting both behavioural and physiological responses to all three stressors (Fig. 3) [90, 91, 115], the oryx exhibited the largest daily fluctuations (up to $7.7^{\circ} \mathrm{C}$ ) of body temperature ever recorded for a large free-living mammal. Their $24 \mathrm{~h}$ maximum body temperatures reached as high as $42.6{ }^{\circ} \mathrm{C}$, while in the early morning, when air temperatures were moderate $\left(26^{\circ} \mathrm{C}\right)$, body temperature dropped to as low as $34.3^{\circ} \mathrm{C}$. The minimum body temperatures that they reached were similar to those observed in other antelope shortly before death associated with inadequate energy [55]. Arguably, of the large mammals studied, the Arabian oryx currently faces the greatest challenge to homeostasis, and is unlikely to survive if environments become much hotter or drier with climate change. Like many other large mammals, the Arabian oryx will not be able to move to more suitable habitats, and, with a small population and slow reproduction, will be unable to adapt through genetic changes within the population.

In addition to the stressors resulting from a changing climate, Arabian oryx survival, like that of other large mammals, is threatened by habitat destruction, interspecific competition, legal and illegal hunting and capture [150]. In the developing world, overhunting is the greatest threat to large mammal survival [7, 151]. Many large mammals also are targeted specifically for high-value trade [152]. Human killing has contributed previously to megafauna extinctions [13] and larger species currently are disproportionately exploited by humans [151, 153]. Conflict with humans is a major cause of adult mortality in large carnivores, both within and outside of protected areas, particularly if the species has a large home range [154]. An analysis of Amazonian mammals with body mass greater than $1 \mathrm{~kg}$ showed that population decline as a result of hunting was negatively correlated with the species' rate of population increase, and positively correlated with longevity and gestation period [151]. Larger mammals, therefore, are more vulnerable than are smaller mammals to extinction as a result of hunting and over-harvesting.

Indeed, the greatest threat to biodiversity is likely to arise from the synergistic effect of various threats. The combined effect of climate change, habitat destruction, and harvesting, for example, will be much larger than the summed individual effect of the stressors [155]. For large mammals, their intrinsic biological traits, which include their life history traits and home range requirements, as well as their phenotypic plasticity available to buffer the changes, will influence their vulnerability. As outlined for ectotherms [156], behaviour is likely to play an important role in buffering large mammals against climate change effects. Understanding how sensitive to climate change a particular population of large mammals is, and what adaptive capacity the individuals may have, therefore requires measurements to be made in freeliving mammals in their current habitats while undergoing their normal activities. As we have shown here, large mammals can exhibit various physiological and behavioural modifications in response to the stressors of food and water shortage, and heat, but responses to buffer a stressor typically incur trade-offs. Maintaining a relatively constant and high body temperature, for example, requires energy and water. Water is required for osmoregulation, while energy is required for growth and reproduction. Depending on their situation, large mammals will need to rank the importance of competing homeostatic systems, and prioritise those with the highest rank, to maximize their fitness. The evidence obtained so far from several large mammal species in their natural habitat indicates that body temperature regulation is sacrificed in the face of water and energy limitation [55]. If that is a response common to all large mammals, then the magnitude of the fluctuation of body temperature for a given species in a particular environment may provide a useful index of stress [51, 55], and a key input variable in models predicting vulnerability of a species to climate change.

Measuring body temperature, and other indices of physiological function and behaviour, in free-living large mammals now can be done using biologging, or biotelemetry. Indeed, the technology for animal-borne sensors has advanced rapidly, such that mammals routinely are being equipped for ecological studies [157]. Although fine-scale data can be obtained, it also is important to understand the factors that drive physiological and behavioural modifications. Nocturnal crop raiding activity by chimpanzees, for example, was associated not with a warming climate and the avoidance of daytime activity, but rather with the avoidance of humans who are in the fields during the day [158]. Also, although biologging overcomes the problem of human observers 
influencing an animal's responses [50], care needs to be taken to minimize the impact of animal-borne sensors or monitoring on an animal's welfare. There can be unexpected consequences; drones (unmanned aerial vehicles) flying above free-living black bears (Ursus americanus), from an apparently reasonable distance so as to avoid animal disturbance, caused stress responses reflected by the heart rates of the bears increasing by as much as 400\% [159]. Paradoxically, therefore, even the remote monitoring of large mammals to understand their responses to climate change can cause stress responses that may affect their survival.

Nevertheless, biologging and remote monitoring of the physiological and behavioural responses of multiple large mammal species is required if we are to better understand their sensitivity and vulnerability to climate change. Our review here is focused mainly on the responses of large herbivores, reflecting a bias of research towards these large mammals. Within herbivores, research efforts also have been focused mainly on game species in wealthy countries [7]. Little is known about the phenotypic plasticity of carnivores, primates, or suids. The approach to understand the responses of large mammals requires long-term monitoring - until now, few studies have extended beyond one year - of many individual animals within a population.

Mechanistic models that have been advanced to predict the effects of climate change on endotherms typically view physiological traits to be fixed within individual species [76]. However, acclimatization to changing stressors and intraspecific differences in a population, in terms of social positioning, reproductive status, and age, may influence an individual's sensitivity and vulnerability to climate change. For example, when food was restricted, subordinate female red deer, surprisingly, achieved a much lower metabolic rate than did dominant females, resulting in less body mass loss [160]. On the other hand, vervet monkeys (Chlorocebus pygerythrus) with a greater number of social partners achieved better regulation of body temperature during winter than did those with fewer relationships [149]. The effect of young individuals in a population also should not be ignored. Young mammals have a smaller surface area to volume ratio, poorer thermal insulation and greater mass-specific metabolic rate than do adults. They therefore will experience a greater increase in body temperature and dehydrate more quickly in a hot environment than will adults. The combined effect of smaller body size and higher mass-specific energy requirements of juvenile, compared to adult, red kangaroos is thought to underlie the finding that juvenile survival is a major driver of population dynamics in that species [161]. The behavioural responses of a group therefore may be dictated by needs of the young, rather than by those of adults.

\section{Conclusions}

Predictive models for the responses of large mammals to climate change therefore require the incorporation of both intraspecific and interspecific variation in traits, together with knowledge of the changing habitat structure and climate. As we have indicated above, there are large gaps in our knowledge of the phenotypic plasticity available to many large species. In addition to understanding that plasticity, modelling a species' responses to climate change requires the incorporation of trophic interactions, including the complex interplay between conspecifics, competitors and predators. The models also require consideration of the field of ecological energetics, which takes a mechanistic approach to ecological interactions by focussing on the fundamental physiology that underpins energy use by organisms and the ability of an organism to harness the required energy in a particular ecological context [162]. By reducing the availability of water and food energy, reduced precipitation is likely to have a major impact on the welfare of large terrestrial mammals. In comparison, large mammals exposed only to a warming climate, but with ready access to drinking water and sufficient food, are likely to be better buffered against the environmental change. Although the macroclimate will affect plant productivity and water availability, microclimates will determine the thermal stress imposed on a mammal. Predictive models of large mammal responses to climate change therefore also need to include microclimate characteristics and availability, as well as a consideration of the capacity of a species to adjust its temporal niche, or to disperse and alter its home range. It has been proposed that a key to conserving wildlife is through protecting particular areas, that is, an area-based approach. However, we agree with Cardillo and colleagues [3] that a species-based approach, with knowledge of the mammal's life history, body size, phenotypic plasticity, genetic variability and ability to move, will likely be more effective for conserving large terrestrial mammals. That approach requires complex models, not yet available, to connect the behaviour, physiology, demography and performance of large mammals as they respond to changing climates.

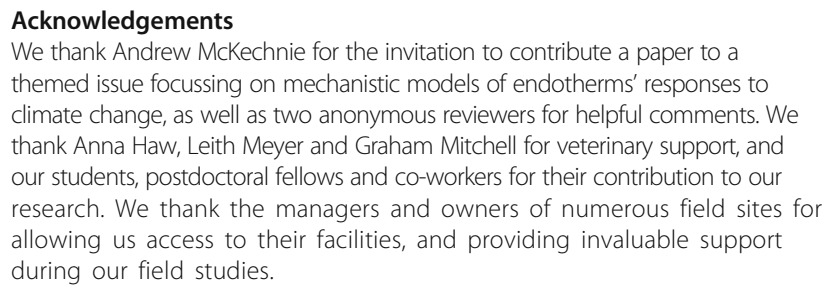

Funding

We thank the South African National Research Foundation (NRF), the Carnegie Corporation of New York, the global change SysTem for Analysis, Research and Training (START), the Oppenheimer Memorial Trust, the Tswalu Foundation, the University of the Witwatersrand, and the Australian Research Council for financial support of our research described in this review. 


\section{Availability of data and materials}

Not applicable.

\section{Author' contributions}

All authors contributed to ideas in this review, all authors revised drafts and approved the final version.

\section{Competing interests}

The authors declare that they have no competing interests.

\section{Consent for publication}

Not applicable.

\section{Ethics approval and consent to participate}

Not applicable to this review of published work.

\section{Author details}

'Brain Function Research Group, School of Physiology, University of the Witwatersrand, Johannesburg, South Africa. ${ }^{2}$ School of Anatomy, Physiology, and Human Biology, University of Western Australia, Crawley 6009, Australia. ${ }^{3}$ School of Animal, Plant and Environmental Sciences, University of the Witwatersrand, Johannesburg, South Africa.

Received: 22 June 2016 Accepted: 16 November 2016 Published online: 28 November 2016

\section{References}

1. Davidson AD, Hamilton MJ, Boyer AG, Brown JH, Ceballos G. Multiple ecological pathways to extinction in mammals. Proc Natl Acad Sci U S A. 2009;106:10702-5.

2. Hilbers JP, Schipper AM, Hendriks AJ, Verones F, Pereira HM, Huijbregts MAJ. An allometric approach to quantify the extinction vulnerability of birds and mammals. Ecology. 2016;97:615-26.

3. Cardillo M, Cardillo M, Mace GM, Jones KE, Bielby J, Bininda-Emonds ORP, et al. Multiple causes of high extinction risk in large mammal species. Science. 2005:309:1239-41.

4. Di Marco M, Boitani L, Mallon D, Hoffmann M, lacucci A, Meijaard E, et al. A retrospective evaluation of the global decline of carnivores and ungulates. Conserv Biol. 2014;28:1109-18.

5. Craigie ID, Baillie JEM, Balmford A, Carbone C, Collen B, Green RE, et al. Large mammal population declines in Africa's protected areas. Biol Conserv. 2010;143:2221-8.

6. Di Marco M, Buchanan GM, Szantoi Z, Holmgren M, Grottolo Marasini G, Gross D, et al. Drivers of extinction risk in African mammals: the interplay of distribution state, human pressure, conservation response and species biology. Philos Trans R Soc Lond B Biol Sci. 2014;369:20130198.

7. Ripple WJ, Newsome TM, Wolf C, Dirzo R, Everatt KT, Galetti M, et al. Collapse of the world's largest herbivores. Sci Adv. 2015;1:e1400103.

8. Skinner JD, Chimimba CT. The Mammals of the Southern African Subregion. 3rd ed. Cambridge: Cambridge University Press; 2005

9. Smith FA, Lyons SK. How big should a mammal be? A macroecological look at mammalian body size over space and time. Philos Trans R Soc Lond B Biol Sci. 2011;366:2364-78.

10. Jessen C. Temperature regulation in humans and other mammals. Berlin: Springer; 2001

11. Tattersall GJ, Sinclair BJ, Withers PC, Fields PA, Seebacher F, Cooper CE, et al. Coping with thermal challenges: physiological adaptations to environmental temperatures. Compr Physiol. 2012;2:2151-202.

12. Gardner JL, Peters A, Kearney MR, Joseph L, Heinsohn R. Declining body size: a third universal response to warming? Trends Ecol Evol. 2011:26:285-91.

13. Barnosky AD, Koch PL, Feranec RS, Wing SL, Shabel AB. Assessing the causes of late Pleistocene extinctions on the continents. Science. 2004:306:70-5.

14. McCain CM, King SRB. Body size and activity times mediate mammalian responses to climate change. Glob Chang Biol. 2014;20:1760-9.

15. Tøien $\varnothing$, Blake J, Edgar DM, Grahn DA, Heller C, Barnes BM. Hibernation in black bears: independence of metabolic suppression from body temperature. Science. 2011;331:906-9.

16. Hansen PJ. Effects of heat stress on mammalian reproduction. Philos Trans $R$ Soc Lond B Biol Sci. 2009;364:3341-50.
17. Thornton PK, Van De Steeg J, Notenbaert A, Herrero M. The impacts of climate change on livestock and livestock systems in developing countries: a review of what we know and what we need to know. Agric Syst. 2009; 101:113-27.

18. Vetter SG, Ruf T, Bieber C, Arnold W. What is a mild winter? Regional differences in within-species responses to climate change. PLoS One. 2015:10:1-17.

19. Schipper J, Chanson JS, Chiozza F, Cox NA, Hoffmann M, Katariya V, et al. The status of the world's land and marine mammals: diversity, threat, and knowledge. Science. 2008:322:225-30.

20. Rondinini C, Visconti P. Scenarios of large mammal loss in Europe for the $21^{\text {st }}$ century. Conserv Biol. 2015:29:1028-36.

21. Di Minin E, Slotow R, Hunter LTB, Montesino Pouzols F, Toivonen T, Verburg $\mathrm{PH}$, et al. Global priorities for national carnivore conservation under land use change. Sci Rep. 2016;6:23814.

22. Mantyka-Pringle CS, Visconti P, Di Marco M, Martin TG, Rondinini C, Rhodes JR. Climate change modifies risk of global biodiversity loss due to landcover change. Biol Conserv. 2015;187:103-11.

23. Kearney $M$, Porter W. Mechanistic niche modelling: combining physiological and spatial data to predict species' ranges. Ecol Lett. 2009:12:334-50.

24. Kelt DA, Van Vuren DH. The ecology and macroecology of mammalian home range area. Am Nat. 2001;157:637-45.

25. Tamburello N, Côté IM, Dulvy NK. Energy and the scaling of animal space use. Am Nat. 2015;186:196-211.

26. Lindstedt SL, Miller BJ, Buskirk SW. Home range, time, and body size in mammals. Ecology. 1986:67:413-8.

27. Santini L, Di Marco M, Visconti P, Baisero D, Boitani L, Rondinini C. Ecological correlates of dispersal distance in terrestrial mammals. Hystrix, Ital J Mammal. 2013:24:181-6.

28. Garland Jr T. Scaling the energetic cost of transport to body mass in terrestrial mammals. Am Nat. 1983:121:571-87.

29. Taylor CR, Heglund NC. Energetics and mechanics of terrestrial locomotion. Annu Rev Physiol. 1982:44:97-107.

30. Settele J, Scholes R, Betts R, Bunn S, Leadley P, Nepstad D, et al. Terrestrial and inland water systems. In: Field CB, Barros VR, Dokken DJ, Mach KJ, Mastrandrea MD, Bilir TE, et al., editors. Climate change 2014: impacts, adaptation and vulnerability. Part A: global and sectoral aspects, Contribution of Working Group II to the Fifth Assessment Report of the Intergovernmental Panel on Climate Change. Cambridge: Cambridge University Press; 2014

31. Thuiller W, Broennimann O, Hughes G, Alkemade JRM, Midgley GF, Corsi F. Vulnerability of African mammals to anthropogenic climate change under conservative land transformation assumptions. Glob Chang Biol. 2006;12:424-40.

32. Parmesan C. Ecological and evolutionary responses to recent climate change. Annu Ecol Evol Syst. 2006;37:637-69.

33. Williamson D, Williamson J, Ngwamotsoko KT. Wildebeest migration in the Kalahari. Afr J Ecol. 1988:26:269-80

34. Owen-Smith N, Ogutu JO. Changing rainfall and obstructed movements: impact on African ungulates. In: Brodie JF, Post ES, Doak DF, editors. Wild life conservation in a changing climate. Chicago: University of Chicago Press; 2013.

35. Santini L, Cornulier T, Bullock JM, Palmer SCF, White SM, Hodgson JA, et al. A trait-based approach for predicting species responses to environmental change from sparse data: how well might terrestrial mammals track climate change? Glob Chang Biol. 2016;22:2415-24.

36. Seddon PJ. From reintroduction to assisted colonization: moving along the conservation translocation spectrum. Restor Ecol. 2010;18:796-802.

37. Lunt ID, Byrne M, Hellmann JJ, Mitchell NJ, Garnett ST, Hayward MW, et al. Using assisted colonisation to conserve biodiversity and restore ecosystem function under climate change function under climate change. Biol Conserv. 2013:157:172-7.

38. Tarszisz E, Dickman CR, Munn AJ. Physiology in conservation translocations. Conserv Physiol. 2014:2:1-19.

39. Blueweiss AL, Fox H, Kudzma V, Nakashima D, Peters R, Sams S. Relationships between body size and some life history parameters. Oecologia. 2008;37:257-72

40. Lindstedt SL, Calder WA. Body size, physiological time, and longevity of homeothermic animals. Q Rev Biol. 1981;56:1-16.

41. Carey JR, Judge DS. Longevity records: life spans of mammals, birds, amphibians, reptiles, and fish. Odense: Odense University Press; 2000.

42. Smith SJ, Edmonds J, Hartin CA, Mundra A, Calvin K. Near-term acceleration in the rate of temperature change. Nat Clim Chang. 2015;5:333-6. 
43. Diffenbaugh NS, Field CB. Changes in ecologically critical terrestrial climate conditions. Science. 2013;341:486-92.

44. Millar JS, Zammuto RM. Life histories of mammals: an analysis of life tables. Ecology. 1983;64:631-5.

45. Sadleir $\mathrm{R}$. The role of nutrition in the reproduction of wild mammals. J Reprod Fertil Suppl. 1969;6:39-48.

46. Blackburn TM, Gaston KJ. The relationship between animal abundance and body size: a review of the mechanisms. Adv Ecol Res. 1999;28:181-210.

47. Hetem RS, Fuller A, Maloney SK, Mitchell D. Responses of large mammals to climate change. Temperature. 2014;1:115-27.

48. Franks SJ, Hoffmann AA. Genetics of climate change adaptation. Annu Rev Genet. 2012;46:185-208.

49. Parmesan C, Root TL, Willig MR. Impacts of extreme weather and climate on terrestrial biota. Bull Am Meteorol Soc. 2000;81:443-50.

50. Mitchell D, Maloney SK, Jessen C, Laburn HP, Kamerman PR, Mitchell G, et al. Adaptive heterothermy and selective brain cooling in arid-zone mammals. Comp Biochem Physiol B Biochem Mol Biol. 2002;131:571-85.

51. Fuller A, Hetem RS, Maloney SK, Mitchell D. Adaptation to heat and water shortage in large, arid-zone mammals. Physiology. 2014;29:159-67.

52. Schmidt-Nielsen K, Schmidt-Nielsen B, Jarnum SA, Houpt TR. Body temperature of the camel and its relation to water economy. Am J Physiol. 1957;188:103-12.

53. Taylor CR. The eland and the oryx. Sci Am. 1969;220:88-95.

54. Mitchell D, Fuller A, Maloney SK. Homeothermy and primate bipedalism: is water shortage or solar radiation the main threat to baboon (Papio hamadryas) homeothermy? J Hum Evol. 2009;56:439-46.

55. Hetem RS, Maloney SK, Fuller A, Mitchell D. Heterothermy in large mammals: inevitable or implemented? Biol Rev. 2016;91:187-205.

56. Fick LG, Kucio TA, Fuller A, Matthee A, Mitchell D. The relative roles of the parasol-like tail and burrow shuttling in thermoregulation of free-ranging Cape ground squirrels, Xerus inauris. Comp Biochem Physiol A Mol Integr Physiol. 2009;152:334-40.

57. Chappell MA, Bartholomew GA. Activity and thermoregulation of the antelope ground squirrel Ammospermophilus leucurus in winter and summer. Physiol Zool. 1981;54:215-23.

58. Clarke A, Rothery P. Scaling of body temperature in mammals and birds Funct Ecol. 2008;22:58-67.

59. McNab BK. Physiological convergence amongst ant-eating and termiteeating mammals. J Zool. 1984;203:485-510.

60. Nielsen BYB, Hales JRS, Strange S, Juel NJ, Warberg J, Saltin B. Human circulatory and thermoregulatory adaptations with heat acclimation and exercise in a hot, dry environment. J Physiol. 1993;460:467-85.

61. Hetem RS, de Witt BA, Fick LG, Fuller A, Kerley GIH, Meyer LCR, et al. Body temperature, thermoregulatory behaviour and pelt characteristics of three colour morphs of springbok (Antidorcas marsupialis). Comp Biochem Physiol A Mol Integr Physiol. 2009;152:379-88.

62. Walsberg GE. Coat color and solar heat gain in animals. Bioscience. 1983:33:88-91.

63. Hofmeyr MD. Thermal properties of the pelages of selected African ungulates. S Afr J Zool. 1985;20:179-89.

64. Schmidt-Nielsen B, Schmidt-Nielsen K, Houpt TR, Jarnum SA. Water balance of the camel. Am J Physiol. 1965;185:185-94.

65. Finch VA. Thermoregulation and heat balance of the East African eland and hartebeest. Am J Physiol. 1972;222:1374-9.

66. Hetem RS, Mitchell D, De Witt BA, Fick LG, Meyer LCR, Shane K, et al. Cheetah do not abandon hunts because they overheat. Biol Lett. 2013; 9:20130472

67. Meyer LCR, Fick L, Matthee A, Mitchell D, Fuller A. Hyperthermia in captured impala (Aepyceros melampus): a fright not flight response. J Wildl Dis. 2008; 44:404-16.

68. Renecker LA, Hudson RJ. Seasonal energy expenditures and thermoregulatory responses of moose. Can J Zool. 1986;64:322-7.

69. McCann N, Moen R, Harris T. Warm-season heat stress in moose (Alces alces). Can J Zool. 2013;91:893-8.

70. Best RC. Thermoregulation in resting and active polar bears. J Comp Physiol B Biochem Syst Environ Physiol. 1982;146:63-73.

71. Whiteman JP, Harlow HJ, Durner GM, Anderson-Sprecher R, Albeke SE, Regehr EV, et al. Summer declines in activity and body temperature offer polar bears limited energy savings. Science. 2015;349:295-8.

72. Khaliq I, Hof C, Prinzinger R, Böhning-Gaese K, Pfenninger M. Global variation in thermal tolerances and vulnerability of endotherms to climate change. Proc Biol Sci. 2014;281:20141097.
73. Buckley LB, Hurlbert AH, Jetz W. Broad-scale ecological implications of ectothermy and endothermy in changing environments. Glob Ecol Biogeogr. 2012;21:873-85.

74. Kingma BR, Frijns AJH, Schellen L, van Marken Lichtenbelt WD. Beyond the classic thermoneutral zone, Including thermal comfort. Temperature. 2014;1:142-9.

75. McCutcheon $L J$, Geor RJ. Influence of training on sweating responses during submaximal exercise in horses. J Appl Physiol. 2000;89:2463-71.

76. Boyles JG, Seebacher F, Smit B, McKechnie AE. Adaptive thermoregulation in endotherms may alter responses to climate change. Integr Comp Biol. 2011:51:676-90.

77. Robertshaw D. Mechanisms for the control of respiratory evaporative heat loss in panting animals. J Appl Physiol. 2006;101:664-8.

78. Dunkin RC. From tissues to landscapes: how thermal physiology, water use, and climate influence patterns of landscape use in elephants. Santa Cruz: University of California; 2012

79. Dunkin RC, Wilson D, Way N, Johnson K, Williams TM. Climate influences thermal balance and water use in African and Asian elephants: physiology can predict drivers of elephant distribution. J Exp Biol. 2013:216:2939-52.

80. Weissenböck NM, Arnold W, Ruf T. Taking the heat: thermoregulation in Asian elephants under different climatic conditions. J Comp Physiol B Biochem Syst Environ Physiol. 2012;182:311-9.

81. D'Araujo SR. The relationship between body and environmental temperature in savanna elephants. Pretoria: University of Pretoria; 2015.

82. Ingram DL. Heat loss and its control in pigs. In: Monteith JL, Mount LE, editors. Heat loss from animals and man. London: Butterworths; 1974.

83. Jenkinson DM. Comparative physiology of sweating. Br J Dermatol. 2006:88:397-406.

84. Fuller A, Maloney SK, Kamerman PR, Mitchell G, Mitchell D. Absence of selective brain cooling in free-ranging zebras in their natural habitat. Exp Physiol. 2000;85:209-17.

85. Musewe VO, Maloiy GMO, Kanja JK. Evaporative water loss in two small African antelopes: the dik-dik and the suni. Comp Biochem Physiol - C Comp Pharmacol. 1976:53:17-8.

86. Dawson TJ, Robertshaw D, Taylor CR. Sweating in the kangaroo: a cooling mechanism during exercise, but not in the heat. Am J Physiol Regul Integr Comp Physiol. 1974;227:494-8.

87. Needham AD, Dawson TJ, Hales JRS. Forelimb blood flow and saliva spreading in the thermoregulation of the red kangaroo, Megaleia rufa. Comp Biochem Physiol A Mol Integr Physiol. 1974:49:555-65.

88. Liow LH, Fortelius M, Bingham E, Lintulaakso K, Mannila H, Flynn L, et al. Higher origination and extinction rates in larger mammals. Proc Natl Acad Sci U S A. 2008;105:6097-102.

89. Cain III JW, Krausman PR, Rosenstock SR, Turner JC. Mechanisms of thermoregulation and water balance in desert ungulates. Wildl Soc Bull. 2013;34:570-81.

90. Ostrowski S, Williams JB, Ismael K. Heterothermy and the water economy of free-living Arabian oryx (Oryx leucoryx). J Exp Biol. 2003;206:1471-8.

91. Hetem RS, Strauss WM, Fick LG, Maloney SK, Meyer LCR, Shobrak M, et al. Activity re-assignment and microclimate selection of free-living Arabian oryx: responses that could minimise the effects of climate change on homeostasis? Zoology. 2012;115:411-6.

92. Hetem RS, Maloney SK, Fuller A, Meyer LCR, Mitchell D. Validation of a biotelemetric technique, using ambulatory miniature black globe thermometers, to quantify thermoregulatory behaviour in ungulates. J Exp Zool. 2007;307A:342-56

93. Hetem RS, De Witt BA, Fick LG, Fuller A, Maloney SK, Meyer LCR, et al. Effects of desertification on the body temperature, activity and water turnover of Angora goats. J Arid Environ. 2011;75:20-8.

94. Mole MA, DAraujo SR, Van Aarde RJ, Mitchell D, Fuller A. Coping with heat: behavioural and physiological responses of savanna elephants in their natural habitat. Conserv Physiol. 2016;4:1-11.

95. Hetem RS, Mitchell D, Maloney SK, Meyer LC, Fick LG, Kerley Gl, et al. Fever and sickness behavior during an opportunistic infection in a free-living antelope, the greater kudu (Tragelaphus strepsiceros). Am J Physiol Regul Integr Comp Physiol. 2008:294:246-54.

96. Hetem RS, Maartin W, Fick LG, Kevin S. Does size matter? Comparison of body temperature and activity of free-living Arabian oryx (Oryx leucoryx) and the smaller Arabian sand gazelle (Gazella subguttouosa) in the Saudi desert. J Comp Physiol B Biochem Syst Environ Physiol. 2012; 182:437-49. 
97. Roberts JA, Coulson G, Munn AJ, Kearney MR. A continent-wide analysis of the shade requirements of red and western grey kangaroos. Temperature. 2016;8940:1-14.

98. Maloney SK, Moss G, Mitchell D. Orientation to solar radiation in black wildebeest (Connochaetes gnou). J Comp Physiol A. 2005;191:1065-77.

99. Hofmeyr MD, Louw GN. Thermoregulation pelage conductance and renal function in the desert-adapted springbok, Antidorcas marsupialis. J Arid Environ. 1987;13:137-51

100. Hut RA, Kronfeld-Schor N, van der Vinne V, De la Iglesia $H$. In search of a temporal niche: Environmental factors. Prog Brain Res. 1st ed. Elsevier B.V.; 2012;199:281-304.

101. Nagy KA, Knight MH. Energy, water, and food use by springbok antelope (Antidorcas marsupialis) in the Kalahari Desert. J Mammal. 1994:75:860-72.

102. Bourgoin G, Garel M, Blanchard P, Dubray D, Maillard D, Gaillard J-M. Daily responses of mouflon (Ovis gmelini musimon $\times$ Ovis sp.) activity to summer climatic conditions. Can J Zool. 2011:89:765-73.

103. Tattersall I. The concept of cathemerality: history and definition. Folia Primatol. 2006;77:7-14

104. Silanikove $\mathrm{N}$. The struggle to maintain hydration and osmoregulation in animals experiencing severe dehydration and rapid rehydration: the story of ruminants. Exp Physiol. 1994:79:281-300.

105. Walsberg GE. Small mammals in hot deserts: some generalizations revisited. Bioscience. 2000;50:109-20.

106. Mitchell D, Laburn HP, Nijland MJM, Zurovsky Y, Mitchell G. Selective brain cooling and survival. S Afr J Sci. 1987;83:598-604.

107. Ostrowski S, Williams JB, Mésochina P, Sauerwein H. Physiological acclimation of a desert antelope, Arabian oryx (Oryx leucoryx), to long-term food and water restriction. J Comp Physiol B Biochem Syst Environ Physiol. 2006;176:191-201.

108. Finch VA, Robertshaw D. Effect of dehydration on thermoregulation in eland and hartebeest. Am J Physiol Regul Integr Comp Physiol. 1979;6:R192-6.

109. Jessen C, Dmi'el R, Choshniak I, Ezra D, Kuhnen G. Effects of dehydration and rehydration on body temperatures in the black Bedouin goat. Pflugers Arch Eur J Physiol. 1998:436:659-66.

110. Jessen C. Brain cooling: an economy mode of temperature regulation in artiodactyls. News Physiol Sci. 1998;13:281-6.

111. Fuller A, Meyer LCR, Mitchell D, Maloney SK. Dehydration increases the magnitude of selective brain cooling independently of core temperature in sheep. Am J Physiol Regul Integr Comp Physiol. 2007;293:438-46.

112. Kuhnen $\mathrm{G}$. Selective brain cooling reduces respiratory water loss during heat stress. Comp Biochem Physiol A Mol Integr Physiol. 1997;118:891-5.

113. Strauss WM, Hetem RS, Mitchell D, Maloney SK, Meyer LCR, Fuller A. Selective brain cooling reduces water turnover in dehydrated sheep. PLoS One. 2015;10:1-18.

114. Baker MA, Doris PA. Effect of dehydration on hypothalamic control of evaporation in the cat. J Physiol. 1982;322:457-68.

115. Hetem RS, Strauss WM, Fick LG, Maloney SK, Meyer LCR, Fuller A, et al. Selective brain cooling in Arabian oryx (Oryx leucoryx): a physiological mechanism for coping with aridity? J Exp Biol. 2012;215:3917-24.

116. Maloney SK, Fuller A, Mitchell G, Mitchell D. Brain and arterial blood temperatures of free-ranging oryx (Oryx gazella). Pflugers Arch Eur J Physiol. 2002:443:437-45.

117. Fukuta K, Kudo H, Sasaki M, Kimura J, Bin Ismail D, Endo H. Absence of carotid rete mirabile in small tropical ruminants: implications for the evolution of the arterial system in artiodactyls. J Anat. 2007;210:112-6.

118. Strauss WM, Hetem RS, Mitchell D, Maloney SK, Meyer LCR, Fuller A. Three African antelope species with varying water dependencies exhibit similar selective brain cooling. J Comp Physiol B. 2016;186:527-40.

119. Mitchell G, Lust A. The carotid rete and artiodactyl success. Biol Lett. 2008:4:415-8

120. Hetem RS, Strauss WM, Fick LG, Maloney SK, Meyer LCR, Shobrak M, et al. Variation in the daily rhythm of body temperature of free-living Arabian oryx (Oryx leucoryx): does water limitation drive heterothermy? J Comp Physiol B Biochem Syst Environ Physiol. 2010;180:1111-9.

121. Jessen C, Laburn HP, Knight MH, Kuhnen G, Goelst K, Mitchell D. Blood and brain temperatures of free-ranging black wildebeest in their natural environment. Am J Physiol Regul Integr Comp Physiol. 1994;267:R1528-36.

122. Adolph EF. Tolerance to heat and dehydration in several species of mammals. Am J Physiol. 1947;151:564-75.

123. Bouchama A, Roberts G, Al Mohanna F, El-Sayed R, Lach B, Chollet-Martin S, et al. Inflammatory, hemostatic, and clinical changes in a baboon experimental model for heatstroke. J Appl Physiol. 2005;98:697-705.
124. Brain C. Activity of water-deprived baboons (Papio ursinus) during intertroop encounters. S Afr J Sci. 1991;87:221-2

125. Williams JB, Ostrowski S, Bedin E, Ismail K. Seasonal variation in energy expenditure, water flux and food consumption of Arabian oryx Oryx leucoryx. J Exp Biol. 2001;204:2301-11.

126. Nagy KA, Peterson CC. Scaling of water flux rate in animals. Berkeley: University of California Press; 1988.

127. Bothma JDP, Le Riche EAN. Aspects of the ecology and the behavior of the leopard in the kalahari desert. Koedoe. 1984;27:259-79.

128. Long RA, Bowyer RT, Porter WP. Behavior and nutritional condition buffer a large-bodied endotherm against direct and indirect effects of climate. Ecol Monogr. 2014;84:513-32.

129. Calder WA. Size, function and life history. Mineola: Dover Publications; 1996.

130. Humphries MM, Umbanhowar J, McCann KS. Bioenergetic prediction of climate change impacts on northern mammals. Integr Comp Biol. 2015: 44:152-62.

131. Vors LS, Boyce MS. Global declines of caribou and reindeer. Glob Chang Biol. 2009;15:2626-33.

132. Bronson FH. Climate change and seasonal reproduction in mammals. Philos Trans R Soc Lond B Biol Sci. 2009:364:3331-40.

133. Post E, Forchhammer MC, Adams LG, Singer FJ, Dale BW, Albon SD, et al. Climate change reduces reproductive success of an Arctic herbivore through trophic mismatch. Philos Trans R Soc Lond B Biol Sci. 2008;363: 2369-75.

134. Speakman JR, Kro'l E. Maximal heat dissipation capacity and hyperthermia risk: neglected key factors in the ecology of endotherms. J Anim Ecol. 2010; 79:726-46.

135. McCue MD. Starvation physiology: Reviewing the different strategies animals use to survive a common challenge. Comp Biochem Physiol A Mol Integr Physiol. 2010;156:1-18.

136. Arnold W, Ruf T, Reimoser S, Tataruch F, Onderscheka K, Schober F. Nocturnal hypometabolism as an overwintering strategy of red deer (Cervus elaphus). Am J Physiol Regul Integr Comp Physiol. 2004;286:174-81.

137. Signer C, Ruf T, Arnold W. Hypometabolism and basking: the strategies of Alpine ibex to endure harsh over-wintering conditions. Funct Ecol. 2011:25:537-47.

138. Arnold W, Ruf T, Kuntz R. Seasonal adjustment of energy budget in a large wild mammal, the Przewalski horse (Equus ferus przewalskii) II. Energy expenditure. J Exp Biol. 2006;209:4566-73.

139. Brinkmann L, Gerken M, Riek A. Adaptation strategies to seasonal changes in environmental conditions of a domesticated horse breed, the Shetland pony (Equus ferus caballus). J Exp Biol. 2012;215:1061-8.

140. Sheriff MJ, Fridinger RW, Tøien $\varnothing$, Barnes BM, Buck CL. Metabolic rate and prehibernation fattening in free-living arctic ground squirrels. Physiol Biochem Zool. 2013:86:515-27.

141. Fuller A, Kamerman PR, Maloney SK, Matthee A, Mitchell G, Mitchell D. A year in the thermal life of a free-ranging herd of springbok Antidorcas marsupialis. J Exp Biol. 2005;208:2855-64.

142. Hebert J, Lust A, Fuller A, Maloney SK, Mitchell D, Mitchell G. Thermoregulation in pronghorn antelope (Antilocapra americana, Ord) in winter. J Exp Biol. 2008:211:749-56.

143. Ostrowski S, Williams JB. Heterothermy of free-living Arabian sand gazelles (Gazella subgutturosa marica) in a desert environment. J Exp Biol. 2006;209:1421-9.

144. Maloney SK, Fuller A, Meyer LCR, Kamerman PR, Mitchell G, Mitchell D. Minimum daily core body temperature in western grey kangaroos decreases as summer advances: a seasonal pattern, or a direct response to water, heat or energy supply? J Exp Biol. 2011;214:1813-20.

145. Maloney SK, Meyer LCR, Blache D, Fuller A. Energy intake and the circadian rhythm of core body temperature in sheep. Physiol Rep. 2013;1:e00118.

146. Piccione G, Caola G, Refinetti R. Circadian modulation of starvation-induced hypothermia in sheep and goats. Chronobiol Int. 2002;19:531-41.

147. Arnold W, Beiglböck C, Burmester M, Guschlbauer M, Lengauer A, Schröder $B$, et al. Contrary seasonal changes of rates of nutrient uptake, organ mass, and voluntary food intake in red deer (Cervus elaphus). Am J Physiol Regul Integr Comp Physiol. 2015;309:R277-85.

148. Ostrowski S, Mesochina P, Williams JB. Physiological adjustments of sand gazelles (Gazella subgutturosa) to a boom-or-bust economy: standard fasting metabolic rate, total evaporative water loss, and changes in the sizes of organs during food and water restriction. Physiol Biochem Zool. 2006;79:810-9. 
149. Mcfarland R, Fuller A, Hetem RS, Mitchell D, Maloney SK, Henzi SP, et al. Social integration confers thermal benefits in a gregarious primate. J Anim Ecol. 2015;84:871-8.

150. Ostrowski S, Bedin E, Lenain DM, Abuzinada AH. Ten years of Arabian oryx conservation breeding in Saudi Arabia - achievements and regional perspectives. Oryx. 1998;32:209-22.

151. Bodmer RE, Eisenberg JF, Redford KH. Hunting and the likelihood of extinction of Amazonian mammals. Conserv Biol. 2016;11:460-6.

152. Mcclenachan $L$, Cooper AB, Dulvy NK. Rethinking trade-driven extinction risk in marine and terrestrial megafauna. Curr Biol. 2016;26:1-7.

153. Jerozolimski A, Peres CA. Bringing home the biggest bacon: a cross-site analysis of the structure of hunter-kill profiles in Neotropical forests. Biol Conserv. 2003;111:415-25.

154. Woodroffe R. Edge effects and the extinction of populations inside protected areas. Science. 1998:280:2126-8.

155. Brook BW, Sodhi NS, Bradshaw CJA. Synergies among extinction drivers under global change. Trends Ecol Evol. 2008;23:453-60.

156. Kearney M, Shine R, Porter WP. The potential for behavioral thermoregulation to buffer "cold-blooded" animals against climate warming. Proc Natl Acad Sci U S A. 2009;106:3835-40.

157. Wilmers CC, Nickel B, Bryce CM, Smith JA, Wheat RE, Yovovich V, et al. The golden age of bio-logging: how animal-borne sensors are advancing the frontiers of ecology. Ecology. 2015;96:1741-53.

158. Krief S, Cibot M, Bortolamiol S, Seguya A, Krief JM, Masi S. Wild chimpanzees on the edge: nocturnal activities in croplands. PLoS One. 2014;9:e109925.

159. Ditmer MA, Vincent JB, Werden LK, Tanner JC, Laske TG, laizzo PA, et al. Bears show a physiological but limited behavioral response to unmanned aerial vehicles. Curr Biol. 2015;25:2278-83.

160. Turbill C, Ruf T, Rothmann A, Arnold W. Social dominance is associated with individual differences in heart rate and energetic response to food restriction in female red deer. Physiol Biochem Zool. 2013;86:528-37.

161. Munn AJ, Dawson TJ. Thermoregulation in juvenile red kangaroos (Macropus rufus) after pouch exit: higher metabolism and evaporative water requirements. Physiol Biochem Zool. 2001;74:917-27.

162. Tomlinson S, Arnall SG, Munn A, Bradshaw SD, Maloney SK, Dixon KW, et al. Applications and implications of ecological energetics. Trends Ecol Evol. 2014;29:280-90.

\section{Submit your next manuscript to BioMed Central and we will help you at every step:}

- We accept pre-submission inquiries

- Our selector tool helps you to find the most relevant journal

- We provide round the clock customer support

- Convenient online submission

- Thorough peer review

- Inclusion in PubMed and all major indexing services

- Maximum visibility for your research

Submit your manuscript at www.biomedcentral.com/submit 